\title{
Chinese Perspectives on Tourism Eco-certification
}

\section{Zhong Linsheng}

Chinese Academy of Sciences, China

\section{Ralf Buckley}

International Centre for Ecotourism Research, Griffith University, PMB 50 Gold Coast, Queensland, Australia 4217 r.buckley@griffith.edu.au

\section{Xie Ting}

Chinese Academy of Sciences, China

Tourism eco-certification programs distinguish competing products on environmental grounds (Font, Sanabria and E. Skinner 2003). China has a growing nature and adventure tourism industry (CNTA 2006), and eco-certification is hence a potentially important environmental management tool (Han and Zhuge 2001; Zhuge 2006). Two international schemes have tried to gain acceptance in China, but with little success. On other continents, hundreds of ecotourism products are certified (Ecotourism Australia 2006; Gossling 2006); but in five years, Green Globe 21 (2006) has certified only two hotels, two parks, and one museum in China, and Ecotourism Australia one park (Doole 2005; Zhong, Shidong and Xiang 2003, 2005). Therefore, here, nationally focused Chinese government publications, language research literature, and stakeholder interviews are used to examine progress in internal and international eco-certification, from a national perspective. To map official progress, in 2002, a forum 
recommended codes of conduct and certification systems (China Ecotourism Forum 2003). In 2003, the China National Institute for Standardization hosted an expert meeting on ecotourism certification. In 2005, government tourism and environment agencies endorsed work on ecotourism standards, environmental quality indicators in destinations, and certification of environmental management systems in enterprises (CNTA+SEPA 2005).

In the Chinese-language research literature, eco-certification is discussed by Yu and Shang (2002), Zhong et al (2003, 2005), Song (2004), Bian, Zhang and Wang (2004), Cheng and Zhou (2006), Huang, Cheng and Zhou (2006) and Zhou, Cheng and Zhou (2006). In contrast to the government focus on home-grown programs, their main theme is analysis and applicability of Western schemes. During 2005-2006, the Chinese authors of the present research note conducted detailed semistructured interviews with 20 well-informed stakeholders in categories identified by Song (2005). These include professors from universities and the Chinese Academies of Sciences and Environmental Sciences; senior staff from central and provincial government environmental and tourism agencies; management and staff of tourism and ecotourism companies, and of protected areas; senior staff of international nongovernmental organizations conducting ecotourism projects in China; and representatives of local communities adjacent to national parks used by tourists.

Respondents were asked whether and how China should adopt tourism eco-certification and what factors influence success, including international programs. Asked about specific programs, sites, factors, and organizations with which they were familiar, they 
identified four barriers to international schemes: cost, language, culture, and governance. International programs are expensive, operate in English, and do not match Chinese cultural expectations. For example, cultural traditions for nature appreciation differ between China and the West, affecting ecotourist behaviour, tour operation management, and parks infrastructure design (Li and Cai 2004; Tian 2006; Ye and Xue 2005).

Governance was identified as particularly important. Interviewees agreed with He (2003) that standards and certification in China are the responsibility of central government, not private providers. The country has a National Tourism Standardization Technology Committee which has developed 16 national standards relating to signage, guides, service, hotels, boats, coaches, and travel agents (CNTA+AQSIQ 1993-2004). There are also 23 provincial standards whose coverage includes rural tourism, hotspring tourism, and shopping centers (Ji 2006). In the stakeholders' view, tourism ecocertification programs will only be accepted within the committee's framework, which includes transport and accommodation, attractions and facilities, guides and corporations, and which refers back to regulations that are needed for practical effect.

Respondents argue that to reflect China's social traditions, ecocertification has to be: based in China; designed by Chinese ecologists, parks agencies, and tour operators; run through the National Tourism Standardization Technology Committee; documented in Chinese; regionalized, with local contacts and languages nationwide; run in Chinese currency; and reflecting Chinese prices. Thus it should be home-grown, designed in 
conjunction with provinces and regions, established nationally, and devolved back to the provinces for operation.

Non-Sinophone foreign arrivals to China number only $<20$ million annually, $<1.5 \%$ of the total tourist numbers of 1.34 billion (CNTA 2006), so domestic acceptance of certification schemes is paramount. International recognition of China's efforts could be achieved through the Sustainable Tourism Stewardship Council (Font et al 2003), the World-Wide Fund for Nature (2006), or The Nature Conservancy (2006). But do the same issues apply elsewhere? In particular, if ecotourism is a Western construct as argued by Cater (2006), are such demands also placed on Western nations? The attitudes expressed here by Chinese stakeholders are motivated by a strong sense of social and cultural identity. If these do apply more generally, then domestic eco-certification programs should particularly prevail in countries with few international tourists, weak currencies, few English-speakers, and cultural traditions or expectations which rely on governments for regulated standards, rather than voluntary programs by industry or consumers. In practice, they prevail strongly in Sweden (Gossling 2006), Europe and Latin America (Font and Buckley 2001), and even Australia (Ecotourism Australia 2006).

In summary, stakeholders consider that Chinese tour providers and tourists, who make up $>98.5 \%$ of tourism, want an eco-certification program designed, developed, and delivered within the country itself. Native tourism researchers suggest that international content must be customized to Chinese cultural and commercial circumstances; and government agencies have endorsed continuing work towards a domestic program. These reasons account well for the limited success 
of international schemes, and suggest that the future lies firmly with the development of a domestic program. Therefore, and apart from informing about developments with a Chinese point of view, the present research note raises the issue of the influence and impacts of culture on the expectations, mechanisms, and effectiveness of ecocertification.

Acknowledgements - Funding from the National Natural Sciences Foundation of China, Project 30200040; Chinese Academy of Sciences Institute of Geographical Sciences and Natural Resources Research, Project CXIOG-BO4-04. Interviews conducted under the auspices of the State Environment Protection Administration. 


\section{REFERENCES}

Bian, X., G. Zhang, and S. Wang

2004 Research on Ecotourism and Sustainable Tourism Environment Certification. Resources Development and Market 1:66-69 in Chinese.

Cater, E.

2006 Ecotourism as a Western Construct. Journal of Ecotourism 5:23-39.

Cheng, X., and L. Zhou

2006 Review on Ecotourism Certification Overseas. World Forestry Research 19 (1):1-5 in Chinese.

China Ecotourism Forum

2003 Recommendations about Chinese Ecotourism Development. Tourism Tribune 18 (1):59 in Chinese.

\section{CNTA}

2006 Major Statistics of China Tourism in China, 2005 (In Chinese). Beijing: China National Tourism

Administrationhttp://www.cnta.gov.cn/32-lydy/2005/lytj/2005-1.htm (15 April 15 2006).

CNTA+AQSIQ

1993-2004 Tourism Standards LB/T 001-005; GB/T 10001.1-2, 14308, 15731, 15971, 16766-7,17775, 18971-3 (in Chinese). Beijing: CNTA+AQSIQ. 


\section{CNTA+SEPA}

2005 Notice on Further Reinforcement of Tourism Environmental Protection (in Chinese). Beijing: State Environmental Protection Adminstration <http:// www.cnta.com/22-zcfg/05-07-1.htm> (15 June 2006).

Doole, C. 2005 Going beyond the Great Wall: Ecotourism in China. http://www.panda.org/

news_facts/newsroom/features/index.cfm?uNewsID=21813 (15 June 2006).

Ecotourism Australia

2006 All about Ecotourism Australia

<http://www.ecotourism.org.au> (30 December 2006).

Font, X. and R. Buckley, eds.

2001 Tourism Ecolabelling. Oxford: CAB International.

Font, X., R. Sanabria, and E. Skinner

2003 Sustainable Tourism and Ecotourism Certification: Raising Standards and Benefits. Journal of Ecotourism 2:213-218.

Gossling, S.

2006 Tourism Certification in Scandinavia. In Ecotourism in Scandinavia, S. Gossling and J. Hultman, eds., pp. 63-75. Oxford: CABI. 


\section{Green Globe 21}

2006 Green Globe <www.greenglobe.org> (30 December 2006).

Han, N., and R. Zhuge

2001 Ecotourism in China's Nature Reserves: Opportunities and Challenges. Journal of Sustainable Tourism 9:228-242.

He, L.

2003 Discussion on State of Tourism Standardization in China (in Chinese). http://www.cnta.gov.cn/22-zcfg/lvbz/xjyd/03-1.htm (10 June 2006).

Huang, Z., X. Cheng, and L. Zhou 2006 Study on Synthetic Evaluation of Ecotourism Certification (in Chinese). Journal of Nanjing Forestry University 6 (1):70-75.

Ji, G.

2006 Tourism Standardization System Reform and Innovation (in Chinese). http://

www.cnta.com/news_detail/newsshow.asp?id=A2006622152325538 283 (5 July 2006).

Li, Y., and Y. Cai

2004 A Case Study of Ecotourists' Behavioral Characteristics in Baihuashan Nature Reserve, Beijing (in Chinese). Geographical Research 23:863-874.

Song, R. 
2004 Thoughts on Constructing an Ecotourism Accreditation Program in China (in Chinese). Journal of Guilin Institute of Tourism 15 (1):56-61.

2005 On Stakeholders in Ecotourism, with China as an Example (in Chinese). China Population Resources and Environment 15 (1):3641.

The Nature Conservancy

2006 The Nature Conservancy <http://www.nature.org> (31 December).

Tian, $\mathrm{X}$.

2006 The Development of Forest Park in China. Beijing: China Reform Newspaper 2006 (3):29.

World-Wide Fund for Nature

2006 WWF for a Living Planet <http://www.wwf.org> (31 December).

Ye, W., and X. Xue

2005 Research on Indigenous Ecotourism (in Chinese). China Population, Resources and Environment 15 (6):55-61.

Yu, F., and J. Shang

2002 The Necessity and Significance of Implementing Ecotourism Certification (in Chinese). Ecological Economics 5:48-50.

Zhong, L., Z. Shidong, and B. Xiang 
2003 Principles and Methods of Ecotourism Planning (in Chinese). Beijing: Chemistry Industry Press.

Zhong, L., Q. Zheng, and Q. Shi

2005 Opportunities and Challenges in Implementing Ecotourism Accreditation in China (in Chinese). China Population, Resources and Environment 15 (2):112-116.

Zhou, L., X. Cheng, and T. Zhou 2006 Research on Willingness to Pay for Certificated Ecotourism Product: An Empirical Analysis Based on the Tourists of Zhejiang's Four Scenic Spots (in Chinese). Economic Geography 26 (1):140144.

Zhuge, R.

2006 Consulting International Ecotourism Standard and

Standardizing China Ecotourism Market

<http://www.greenglobe21.cn/2006-6/200665213452.htm> (20 June). 